\title{
Sustainable Development and Transition Management: A New Approach for European Peripheral Areas
}

\author{
Vincenzo Provenzano ${ }^{(\bowtie)}$, Maria Rosaria Seminara, \\ and Massimo Arnone \\ SEAS, University of Palermo, Viale delle Scienze Ed.13, 90128 Palermo, Italy \\ vincenzo.provenzano@unipa.it
}

\begin{abstract}
This paper on Europe as a sustainable economy and its policy for peripheral areas contributes to the analysis on the relationship between Transition Management and new approaches to regional development. It follows that regions are different ecosystems which require not only conventional macroeconomic visions for development processes, but also a precise spatial approach based on different levels of geographical aggregation. The physical environment, therefore, becomes a useful element not only to analyse the transition mechanisms, but also as a constitutive part of economic, social and environmental changes in the short, medium and long term. A number of interesting aspects are examined and the concept of Living Labs as a modus operandi of Transition Management is indicated according to the Quintuple Helix model, which requires large-scale public participation, both in the structuring of problems as well as the dynamic change in political agendas. The authors underline how, in an era of constant transformation, ecosystem management contributes to ecological and economic resilience as well as social flexibility needed to deal with and challenge the economic crisis as well as the mistrust that citizens have towards the European institutions. This paper, founded on an ecosystem approach, aims to contribute to the debate on the review of the European Cohesion Policy.
\end{abstract}

Keywords: Transition management $\cdot$ Living labs $\cdot$ Cohesion policy

\section{Introduction}

This study, by taking into consideration the growing inequalities across Europe, offers a first analysis on how to intervene on the Cohesion Policies of the European Union for the period 2021-2027. Horizontal policies, such as infrastructure, human capital and a property rights system, have shown to have positive effects only in developed regions, whilst this has not been the case for the less developed ones. The same quest for "good policies" of the Smart Specialization Strategies (S3) was an important element of the EU 2020 innovation plan whose popularity led to a wide dissemination of concepts and applications in regional contexts. Foray [1] (p. 6) observed that "the high flexibility of the concept of Smart Specialization also entails a great risk": terms such as S3 and entrepreneurial discovery are now routine in EU cohesion policy, however its 
implementation and true impact has shown no significant results on the less developed regions. A variable however that is somewhat overlooked is that of the physical environment, being an essential element of the Quintuple Helix Model.

In this study we address the documented lack of a clear European Cohesion Policy that highlights the need to analyse the link between the transition period after the Great Recession and envisage new guidelines for development in lagging regions. As a prerequisite for said analysis, the first step is to trace Europe as a sustainable economy. In doing so, we aim to establish a new Transition Management concept that could assist as a mixing framework for quality analysis, addressing the role of new notions for sustainability transition and thus allowing for more accurate policy recommendations.

Recent empirical results on the Great Recession Annoni [2] indicate how European regions diverge in their ability to recover from economic shocks. In particular, the core developed regions experience significant growth and spill-over effects to neighbouring regions due to higher investment shares, the presence of an economic structure based on advanced value-added sectors, as well as high quality institutions. In marginal regions, the increase of higher education and training level as well as advanced expertise in information and communication technologies (ICT) all have an influence on the regional GDP per capita.

European policymakers, most likely reassured by these results, confirm the EU's previous Cohesion Policy yet the large economic gap and social discontent in Europe illustrates a different approach. In the second paragraph, we therefore illustrate how Europe is an ecosystem based on its territorial elements. The Transition Management approach is then presented in the third paragraph illustrating it as a sustainable innovation system capable of reacting to a dynamic timeframe. In this setting the implementation of a Quintuple Helix Model together with the Territorial Living Lab are designed to implement an improved and multi-dimensional approach to regional development. In conclusion, the authors explore how certain aspects of a more active role of the environment as a cross-setting variable for growth.

\section{Europe and Peripheral Areas: Sustainability and Local Strategies for Growth}

In September 2015, the United Nations (UN) General Assembly adopted a global development agenda for all countries and stakeholders to use as a blueprint for progress on economic, social, and environmental sustainability. The 2030 Agenda for Sustainable Development and its seventeen Sustainable Development Goals (SDGs) bound 193 Member States to ensure sustained and inclusive economic growth, social inclusion, and environmental protection, fostering peaceful, just, and inclusive societies through a new global partnership.

Europe intends to adopt the objectives outlined in the 2030 Agenda. The implementation of these objectives involves the evolution from a linear to a circular economy, the sustainability from farm to consumer, creating a global food and agriculture system, a clean and resilient energy sector, as well as a regulated social investment system, which includes education, healthcare, gender equality and rural development. We are therefore obliged to balance out the different aspects such as economic, social, 
environmental, as well as institutional sustainable development. In this perspective, Cohesion Policy at European level should play a key role by further promoting integration and economic and social equality.

The main objective of the European Cohesion Policy is the reduction of structural gaps, at both international as well as intranational level. Growth differentials are at the heart of the continuing European debate which questions the mechanisms underlying the growing gaps as opposed to the supporters of automatic economic convergence processes.

EU regional and urban development policies defined as Cohesion Policies account for approximately a third of the EU's multiannual budget. A fundamental characteristic is that Cohesion Policy is managed according to a multilevel governmental scheme that includes national governments, regional administration and local communities [3].

In recent years the economic and social results have been widely discussed with opposing views: one study indicates that the differentials have increased [4], whereas other authors believe that they have diminished [5]. Cohesion policies in particular, tend to favour the most competitive European areas by increasing regional gaps. The new Cohesion Policy 2021-2027 appears, however, to place resources where they are most needed. The new criteria include the areas that have higher levels of youth unemployment, low levels of education, measures related to climate change and the level of migrant integration. The 2021-2027 Cohesion Policy framework goes even further at a local level: it supports the development of local growth strategies by urban, local or other territorial authorities, which are now expected to be put in charge of, or at least involved in, the selection of EU-funded projects. It also supports the continuation of "Community-Led Local Development", namely the creation of local growth strategies by action groups involving local authorities, civil society and business partners.

The socio-economic inequalities between different geographical regions are a challenge faced by many countries. The core-periphery model links the interrelated gaps in demographic and economic conditions to the spatial fields. Since the "core" is a highly urbanized region in which both population and economic activity are concentrated, the "periphery" is distinguished from the core by its sparse population and lagging economic development [6]. The concentration of long-term unemployment, education deficit, growing poverty and outward migration of residents, are often associated with peripheral and low-growth regions. Such regions can be found in both developed as well as less developed countries.

It is therefore necessary to look at the growing disparity between central and bordering or rural areas. In the European Union (EU), rural regions cover $57 \%$ of the territory and include $24 \%$ of the population [7].

Rural regions face significant challenges in comparison to other regions [8]. Rural territories are characterized from distance to markets and services [9] as well as from a decline in employment in dominant agricultural sector [10]. The major difficulties encountered in these areas are the absence of employment opportunities, [11] and limited access to public services such as education and health [12]. The question of rural development is on the agenda of various governments and institutions like the European Commission, OECD and the United Nations [13]. The progressively rising depopulation of rural areas has led European governments to devise strategies to 
encourage the development of these areas and their connected sectors. Unbalanced development is a typical feature of the European economic landscape. It is for this reason that it remains essential, in line with the principle of solidarity, to promote discussions on territorial production and wealth in Europe. The initial structural characteristics and diverging dynamics in terms of industry decline, and growth of high productivity services, explain the presence of distinctive regions which require specific economic policy action needed for recovery and structural change.

Recent empirical studies based on a neoclassical growth modelling approach [2] demonstrate how the core European regions have better institutions, and an economy specialised in higher-value-added sectors significantly boost domestic growth, and how increased investment also induces positive spill-over effects to neighbouring regions.

In other words, macroeconomic approaches to growth presuppose the existence of unique models, abstractly conceived and applicable to any territorial context. In doing so, economic laws overlook the territory that exclusively represents the place which causes the effects of general development process, that is a "container space" of economic and social processes.

It is therefore possible to say that regional policies play a leading role particularly in those regions that are in disadvantaged areas. The involvement of local actors becomes fundamental in the development of their territory. Sociological and economic theories confirm the existence of possible synergy effects in the implementation of development policies, deriving from the dialogue between institutions and civil society, expanding the number of subjects participating in the definition of a local growth strategy [14]. An ongoing debate is that of the quality and hierarchy of government related to the degree of administrative decentralization. The accountability for regional prosperity may be managed at central or local level, suggesting, in the second case, a transition towards a neoliberal vision of the governance process as a guarantor of the citizens' well-being and autonomy.

In this context, the place-based related to new regional development ideas [15] open new aspects of analysis. A place-based strategy may be used to identify positive elements for territorial development to decipher the main configurations of the social and relational structures existing in the territory [16].

At local level, the founding elements of development, the availability of natural resources, input factors and infrastructure, namely the presence of a combination of advantages, open new distinctive means of growth with significant a level of entrepreneurial creativity and discovery. An innovative combination of local factors determines synergies and agglomerate new ways of cooperation processes [17]. Furthermore, the presence of public-private networks, attractive cultural and natural environments, as well as the presence of processes which increase innovation, are all crucial elements in the low-income areas. In this way an eco-system innovation approach becomes a key factor in the development of marginal areas, both in terms of diversification and increased competitiveness, as well as in relation to new forms of governance [18]. 


\section{Transition Management: A New Vision for Sustainable Development}

The European Union has spoken of ecological transition by treating it at as a challenge for the future of the Union as well as the whole world, and treating it as a fertile ground for new economic possibilities [19]. The transition can be defined as an emerging approach to facilitate the processes of change and innovation towards a more sustainable future. Sustainable Transition is becoming increasingly popular to study and develop multi-dimensional and long-term systemic innovation processes towards new methods of production and sustainable consumption. Sustainable Transition must embrace a systemic approach that, in addition to considering individual problems and sectors, must be positioned at a wider level to solve complex problems and facilitate the identification of connections and feedback between the various components; [20, 21].

Sustainable development goals can be achieved through a shared vision and a structured process, meaning a Transition Management approach could potentially change society in the middle and the long term. The current policy of innovation processes has not brought the expected results as demonstrated by the widening of territorial gaps between EU Member States. The unidirectional approach of development policies has not achieved the expected results. Transition Management disrupts the old planning technique and it implements a model with a more process-oriented approach. The Transition Management method can be considered as a model that combines growth, innovation, and the environment. These topics are currently the centre of political debate in an era of economic, social and cultural transition such as the one we are experiencing.

The operational structure of Transition Management is divided into four phases: strategic, tactical, operational and reflective [22]. It is a cycle that includes collective structuring of problems, controlled experimentation and an evaluation of the policies in place. The structure is cyclical, there is no starting point, yet these phases can follow one another without a consequential order.

The Transition Management Cycle, [23, 24] is based on the interaction of theoretical reflections and practical experiments.

Transition Management provides transversal tools for solving specific problems. It is characterized by a dynamic vision of social phenomena and a multilevel approach to problem-solving. Its theoretical structure based on dynamic and complex systems is reinforced by an operating system divided into four phases which directly involves the social players (Fig. 1). 


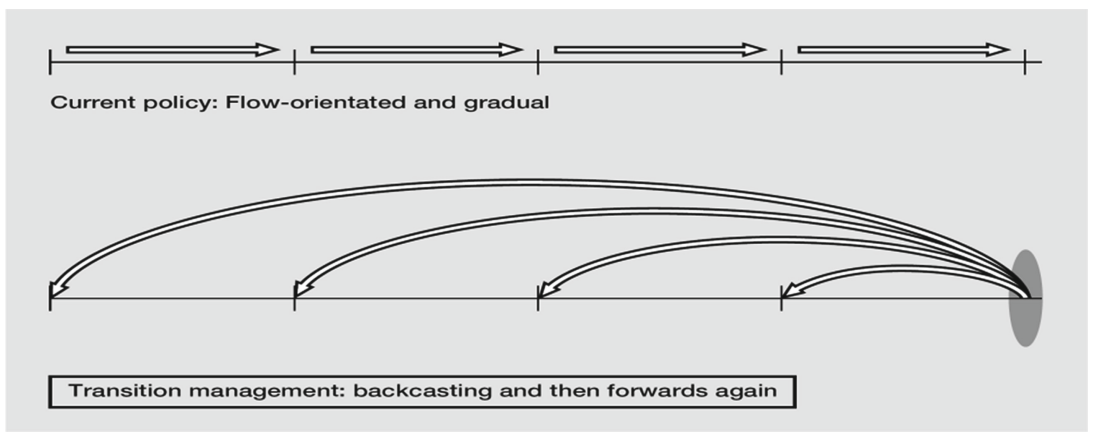

Fig. 1. Short-term linear versus long-term dynamic policy. (Rotmans, 2001)

In this context Living Labs are "new ways of managing innovation processes. The underlying idea is that people's ideas, experiences, and knowledge, as well as their daily needs of support from products, services, or applications, should be the starting point in innovation" [25]. The Living Labs can be designed as a tool for a more effective implementation of the new Cohesion Policy 2021-2027 inside the Quintuple Helix Innovation System Framework [26].

In this way, the Quintuple Helix adopts the formation of a constructive state encompassing ecology, knowledge and innovation, and creating extensive synergy between economy, society and democracy.

The implementation of the Quintuple Helix Model requires the innovate to issues regarding the socio-ecological context in which we live and (co-)develop our common socio-technological future [27]. By implementing a Quintuple Helix Model via the territorial Living Labs, broader issues raised by the scientific debate could be tackled. In the territorial Living Labs, all innovative areas aim to improve the living conditions of local communities. The local system is also considered as an active subject of the lab with which it fully cooperates. Living Labs is a tool capable of developing and generating tacit and codified knowledge within a specific socio-economic context.

By implementing the Quintuple Helix Model the intrinsic potential of peripheral or lagging areas could be identified and utilized to their advantage. A successful territorial Living Lab can facilitate and balance top-down governance with bottom-up initiatives in the regions. The incorporation of different stakeholders and interest groups in policymaking processes can be a way of creating durability in the decisions made and the territorial Living Lab, constructed as open innovation model, facilitating the connection among the areas of the different European regions

Living Labs with their operational concreteness capture the dynamism of modern economic and social systems thanks to the flexibility that makes the implementation of the Transition Management Cycle feasible. Operational, experimentation, reflection, monitoring and control phases are managed directly in the areas involved. The Living Lab is a tool that can develop, generate and transfer tacit and codified knowledge within a specific socio-economic context.

The Living Labs and the Quintuple Helix indicate the ability to bring user, technology and business into an ongoing ground-breaking development process that creates 
real-life environments. These concepts support long-term cooperation, co-creative research, and development by involving the user in the innovation process for 'sensing, prototyping, validating and refining complex solutions in multiple and evolving reallife contexts. The long-term cooperation between researchers, companies, and endusers revert traditional methods and the Quintuple Helix is able to boost assets which in a classical non-spatial economic model tend not to be valorised.

\section{Conclusions}

This paper on Europe as a sustainable economy and its policy for marginal areas contributes to the analysis on the relationship between Transition Management and new conducts of regional development in three ways.

First, the Quintuple Helix Innovation Framework identifies the importance of the environment within the processes of innovation and regional development. It follows that regions and local areas are different ecosystems and therefore require not only conventional macroeconomic visions for development processes but also an ecosystem approach. Second, the paper aims to define Transition Management as a specific ecosystem change process. The environment, therefore, becomes a useful element not only to analyse the transition mechanisms, but as a constitutive element of economic, social and environmental changes in the short, medium and long term. Third, we acknowledge that intervention policies cannot be linear but follow a complex trend, with continuous backward induction processes, requiring a high degree of flexibility.

In this regard the paper aims to underline certain aspects of the role of policy in sustainable transition, and some motives for which the European Union decided to review its approach for the 2021-2027 programming period. The main reason, in short, is a common discontent amongst citizens regarding increased inequality across areas. The environment, therefore, become a cross-setting variable for change.

The results suggest some interesting trends. First, the approach of continuous adjustment is more suitable in economically and socially vulnerable areas, much more sensitive and less resilient in the presence of external shocks. Second, the peripheral areas may exploit new opportunities deriving from the economic and social innovation in their respective specific territories, avoiding any exogenous model of innovation. Third, Transition Management is a modus operandi that fits easily as an open model: it adapts to local economic systems and captures the dynamism and complexity of economic and social phenomena. It also proposes a multi-layered structure with the involvement of different social actors. Finally, it is a model that makes democracy a necessary condition for its application, requiring broad public participation both in the structuring of problems and in the control of the political agenda.

On the other hand, there appears to be an imminent limitation at this stage of analysis. As a policy tool, the building capacity of lagging regions to adopt a flexible approach related to the logical framework of Transition Management requires a specific governance method able to quickly re-evaluate all different paths of development. A corollary of this potential drawback is the implementation of reliable and welldefined indicators needed to support the decision-making process. 
The authors underline how we are now in an era of a deep transformation in which ecosystem management must build and maintain ecological and economic resilience, as well as the need for social flexibility in order to cope with economic and territorial issues, innovate, and adapt.

At this stage precise results cannot be portrayed. However, it is clear that a successful environmental Living Lab can facilitate and offset top-down governance with bottom-up initiatives in a local area. This study most likely outlines an operating method as opposed to indicating a model of analysis. Nevertheless, certain observations may prove useful in the wider debate about the difficulty of applying policy in terms of its ability to reduce economic and territorial disparity between and within European regions, which remains a significant challenge for Europe and its Cohesion Policy.

Acknowledgment. The authors would like to thank the anonymous reviewers for the constructive feedback.

This research is part of the TREnD project (Transition with Resilience for Evolutionary Development), which has received funding from the European Union's Horizon 2020 research and innovation program under the Marie Skłodowska-Curie grant agreement No. 823952.

\section{References}

1. Foray, D.: The concept of the "Entrepreneurial Discovery Process". In: Kyriakou, D., Martinez, M.I., Perianez-Forte, I., Rainoldi, A. (eds.) Governing Smart Specialisation. Routledge (2017)

2. Annoni, P., De Dominicis, L., Prognos, N.K.: The Great Recession: Main Determinants of Regional Economic Resilience in the EU. EU Working Paper, December 2019

3. Fratesi, U., Wishlade, F.G.: The impact of European Cohesion Policy in different contexts. Reg. Stud. 51(6), 817-821 (2017)

4. Leonardi, R.: Cohesion in the European Union. Reg. Stud. 40(2), 155-166 (2006)

5. Boldrin, M., Canova, F.: Inequality and convergence in Europe's regions: Reconsidering European regional policies. Econ. Pol. 32, 205-253 (2001)

6. Friedmann, J.: Urbanization, Planning, and National Development. SAGE Publications, London (1973)

7. European Commission: Staff Working Document a View of Employment, Growth and Innovation in Rural Areas. European Commission, Brusssels (2012)

8. Brown, D.L., Schafft, K.A.: Rural People \& Communities in the 21st Century: Resilience \& Transformation. Polity Press, Cambridge (2011)

9. OECD: The New Rural Paradigm Policies and Governance. OECD, Paris (2006)

10. Terluin, I.J.: Differences in economic development in rural regions of advanced countries: an overview and critical analysis of theories. J. Rural Stud. 19(3), 327-344 (2003)

11. Bosworth, G.: Characterising rural businesses-tales from the paperman. J. Rural Stud. 28(4), 499-506 (2012)

12. Lehmann, U., Dieleman, M., Martineau, T.: Staffing remote rural areas in middle- and lowincome countries: a literature review of attraction and retention. BMC Health Serv. Res. 8, 19 (2008). https://doi.org/10.1186/1472-6963-8-19

13. Pato, M.L., Teixeira, A.: Twenty years of rural entrepreneurship: a bibliometric survey. Soc. Ruralis 56, 1-26 (2014). https://doi.org/10.1111/soru.12058 
14. Ruzza, C.: Europe and Civil Society: Movement Coalitions and European Governance. Manchester University Press, Manchester-New York (2004)

15. Barca, F.: An Agenda for a Reformed Cohesion Policy: A Place-Based Approach to Meeting European Union Challenges and Expectations. Independent Report Prepared at the Request of the European Commissioner for Regional Policy. Danuta Hübner. European Commission, Brussels (2009)

16. Provenzano, V., Arnone, M., Seminara, M.R.: The links between smart specialisation strategy, the quintuple helix model and living labs. In: Bisello, A., Vettorato, D., Laconte, P., Costa, S. (eds.) SSPCR 2017. GET, pp. 563-571. Springer, Cham (2018). https://doi.org/10. 1007/978-3-319-75774-2_38

17. Camagni, R.: Le ragioni della coesione territoriale: contenuti e possibili strategie di policy. Sci. Reg. III(2), 97-111 (2004)

18. Provenzano, V., Seminara, M.R.: Europe 2020 strategy and new policies for marginal areas. Adv. Eng. 11, 53-58 (2014)

19. European Commission. Reflection paper towards a sustainable Europe by 2030, Bruxelles (2019)

20. Geels, F.W.: Technological transitions as evolutionary reconfiguration processes: a multilevel perspective and a case-study. Res. Pol. 31(8-9), 1257-1274 (2002)

21. Rotmans, J., Kemp, R., Van Asselt, M.: More evolution than revolution: transition management in public policy. Foresight 3(1), 15-31 (2001)

22. Loorbach, D.: Transition management: governance for sustainability. In: Conference Governance and Sustainability 'New Challenges for the State, Business and Civil Society', Berlin (2002)

23. Loorbach, D.: Transition Management: New Mode of Governance for Sustainable Development. International Books, Utrecht (2007)

24. Loorbach, D., Rotmans, J.: Managing transitions for sustainable development. In: Xander, O., Wieczorek, A. (eds.) Understanding Industrial Transformation - Views from Different Disciplines, pp. 187-206. Springer, Dordrecht (2006). https://doi.org/10.1007/1-4020-44186_10

25. Bergvall-Kareborn, B., Stahlbros, A.: Living lab: an open and citizen-centric approach for innovation. Int. J. Innov. Reg. Dev. 1(4), 356-370, 200 (2009)

26. Carayannis, E.G., Grigoroudis, E., Campbell, D.F.J., Meissner, D., Stamati, D.: The ecosystem as Helix: an exploratory theory building study of regional co-opetitive entrepreneurial ecosystems as quadruple/quintuple helix innovation models. R\&D Manage. 48(1), 148-162 (2017)

27. Baccarne, B., Logghe, S., Schuurman, D., De Marez, L.: Governing quintuple helix innovation: urban living labs and socio-ecological entrepreneurship. Technol. Innov. Manage. Rev. 6(3), 22-30 (2016) 
Open Access This chapter is licensed under the terms of the Creative Commons Attribution 4.0 International License (http://creativecommons.org/licenses/by/4.0/), which permits use, sharing, adaptation, distribution and reproduction in any medium or format, as long as you give appropriate credit to the original author(s) and the source, provide a link to the Creative Commons license and indicate if changes were made.

The images or other third party material in this chapter are included in the chapter's Creative Commons license, unless indicated otherwise in a credit line to the material. If material is not included in the chapter's Creative Commons license and your intended use is not permitted by statutory regulation or exceeds the permitted use, you will need to obtain permission directly from the copyright holder.

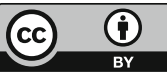

